\title{
Article \\ Implementation of Roma Inclusion Policies: Why Defining the Problem Matters
}

\author{
Joanna Kostka \\ Department of Public Policy, Central European University, 1051 Budapest, Hungary; \\ E-Mail: joanna.kostka@gmail.com
}

Submitted: 28 January 2015 | In Revised Form: 27 April 2015 | Accepted: 5 May 2015 |

Published: 29 September 2015

\begin{abstract}
The concept of "Roma exclusion" has come to dominate political discussions about the marginalization of the largest ethnic minority. Placed at the center of the European Union political agenda, it recognized that Roma poverty has multiple and interrelated causes, which require multifaceted policy responses. Nevertheless, while the concept has acquired strategic connotations, by stressing socio-economic processes it has remained open to different interpretations. These are influenced by political perceptions of Roma identity and minority rights, as well as domestic policy approaches to equality. The pivotal instability in the discourse concerns the question of whether exclusion is a characteristic feature of contemporary European societies or a living condition visited on particular individuals and ethnic groups. This article critically examines the discourse on Roma exclusion adopted in the framework of European cohesion policy. Building on implementation and equality scholarship, it argues that every postulated solution has built into it a particular representation of what the problem is, and it is these representations and their implications that need to be discussed as potential causes of policy success or failure. The article presents key findings from the empirical investigation of Structural Funds (SF) programming (2007-2013) implemented in two convergence regions (Andalusia and Eastern Slovakia), which confirm that domestic discourse shapes the scope and quality of SF Roma inclusion projects.
\end{abstract}

\section{Keywords}

cohesion policy; equality; framing; implementation; minority; Roma-exclusion; Structural Funds

\section{Issue}

This article is part of the special issue "Talking about Roma: Implications for Social Inclusion", edited by Dr. Eben Friedman (Independent Consultant and Senior Non-resident Research Associate, European Centre for Minority Issues, Germany).

(C) 2015 by the author; licensee Cogitatio (Lisbon, Portugal). This article is licensed under a Creative Commons Attribution 4.0 International License (CC BY).

\section{Introduction}

In the last decade, the European Union (EU) has placed the concept of Roma exclusion on its political agenda, demonstrating its willingness to take a leadership role in addressing marginalization of the largest European ethnic minority. Concerned with deteriorating socioeconomic conditions in numerous Roma communities the European Commission (EC) has advised Member States to make full use of the EU's instruments, in particular the system of financial transfers, the Structural Funds (SF) (EC, 2004, p. 42). The fifth report on economic social and territorial cohesion made explicit ref- erence to the Roma- "deemed especially susceptible to social exclusion" and denoted the SF as key instruments for addressing Roma exclusion. Consequently, in the 2007-2013 funding period the majority of Member States made a commitment to formulate Roma inclusion objectives within their SF programming: the $\mathrm{Na}$ tional Strategic Reference Framework (NSRF) and Operational Programmes (OP). In effect an estimated $€ 12.65$ billion was earmarked towards inclusion measures.

While the SF are instruments well suited to address systemic causes of inequality and facilitate changes towards a substantive equality for Roma people, their 
absorption has been highly uneven. The 2011 evaluation reports Support for Enhancing Access to the Labor Market and the Social Inclusion of Migrants and Ethnic Minorities and Roma Thematic Report revealed that certain Member States have made substantial progress developing Roma inclusions measures with the use of SF, while others considerably lagged behind (CSES, 2011a, 2011b). Empirical data collected from 15 Member States indicated Spain as the most "successful" country in terms of absorption and allocation of available funding. In turn, Slovakia exhibited the weakest performance, falling behind other Member States including Hungary, Poland and the Czech Republic ${ }^{1}$.

Similar conclusions emerged from a study commissioned by the European Parliament (EP) Measures to Promote the Situation of Roma EU Citizens in the EU (2011). The evaluation of 12 Member States showed that Spain allocated more ESF budget per capita directly targeting social exclusion of vulnerable citizens than any other member state ${ }^{2}$. Slovakia appeared at the other end of the continuum allocating the least amount in the evaluated sample. Decade Watch Survey (2009) measured the impact of relevant government policies over the span of five years and also placed Spain at the top of the ranking list while giving Slovakia the lowest score. The survey disclosed that the "Spanish model" has been effectively promoting high quality Roma inclusion projects, most pronounced in the area of employment. According to the situational study conducted by the EURoma (2010), Spain has demonstrated a growing number of direct Roma beneficiaries. Vivian Reding, the European Commissioner for Justice, Fundamental Rights and Citizenship praised the Spanish model on numerous occasions for showing "how to use EU funding most effectively and how to use it to promote social cohesion and combat poverty in the Roma communities".

While the existing reports have identified variation in the usage of SF, they provide a largely descriptive picture with little analytical enquiry into the causes of diverging outputs. As a result, it is difficult to understand why the Spanish government has been more successful in using SF.

This article aims to fill this explanatory void by presenting rigorous analysis of implementation processes developed in the Spanish and Slovak system of SF governance, and argues that implementation of SF is strongly influenced by the content of overarching SF inclusion strategies, in particular the representation of Roma exclusion as public problem. Building on a constructivist approach to policy implementation (Bacchi, 1999; Béland, 2005) it asserts that the formulation of Roma inclusion strategies does not follow a rational

\footnotetext{
${ }^{1}$ Bulgarian and Romania were not included in the sample.

${ }^{2}$ The per capita measurement took into consideration the size of the Roma population in each country.
}

choice model whereby policy-makers define Roma exclusion clearly and canvass many (ideally all) alternatives that might ameliorate it. Instead, their actions are often driven by political ideologies, institutional values or normative convictions that dictate what needs to be addressed and how. Goffman (1986) refers to this phenomenon as "framing", a concept implying that articulated problems are not simple descriptions of reality but specific representations that give meaning to reality. Empirical analysis of Spanish and Slovak SF programming shows that such "frames" are translated into judgement and procedures and their implementations have a real effect on policy outputs. With that it challenges common contentions that effective utilization of SF is a result of rational calculations and strong political and administrative capacities of the implementation bodies.

The article is structured as follows. First it reviews existing literature, which accounts for the variation in the use of SF, and presents the adopted methodology. Subsequently, the article discusses the concept of Roma exclusion with the aim to infer the prevailing frames inside cohesion policy discourse. The empirical section demonstrates how the framing of Roma exclusion inside the Spanish and Slovak SF programming impacted the SF outputs in the two convergence regions, Andalusia and Eastern Slovakia. The conclusion summarizes the findings and the implications of the study.

\section{Theoretical Explanations of Diverging SF Outputs}

A common argument for the Spanish success is based on the perception that Spain as a "richer country" has a stronger institutional capacity to absorb and allocate EU funding more efficiently (Leonardi \& Nanetti, 2011). Allegedly, experience with EU procedures made the Spanish government more adept at optimizing available opportunities to address a wide range of issues including the exclusion of the Roma. However, the correlation between administrative efficiency and enhanced equity of undertaken measures is extremely weak. Although efficiency might improve overall public governance, it is highly unlikely that on its own it will promote equal treatment and tackle social exclusion. In fact, numerous studies demonstrate that the drive towards efficiency in European cohesion policy has actually pushed aside the interests of the most vulnerable and weakly organized groups (Bailey \& De Propris, 2002; De Rynck \& McAleavey, 2001). The capacity argument is further weakened by the fact that the Slovak government received substantial financial and technical support during the pre-accession period, aimed precisely at building policy expertise in the area of social exclusion (Guy, 2012) (similar financial support was never provided to Spain).

Another common argument asserts that countries with longer standing EU membership status are more likely to use SF effectively. Most pronounced in socio- 
logical debates about integration, the experience argument assumes that with time Member States acquire knowledge about European rules and procedures and internalize European values (Dąbrowski, 2010). Regular interactions between the EU and domestic policy-makers are thought to set in motion a policylearning process, which with time reduces integration costs, administrative discrepancies and resistance. It is anticipated that with time domestic actors become familiarized with the procedures and supranational expectations which helps them navigate better through the system and optimize all its potential benefits (Ezcurra, Pascual, \& Rapún, 2007). This argument, however, fails to explain why countries with similar duration in membership are not equally effective in utilization of $\mathrm{SF}^{3}$. More importantly it cannot explain the particular circumstances of the Spanish and Slovak cases. The Spanish government began to use SF for Roma integration only a decade after the country's accession, meaning it had approximately the same amount of time as the Slovak authorities to develop Roma inclusion strategies within national SF programming. Thus it remains unclear why Spanish policy-makers would learn "faster and better" than Slovak ones, especially if one takes into account the introduction of strategic inclusion tools by the Slovak government-the horizontal priority Marginalized Roma Community which required each OP to designate a section describing how general measures will contribute to Roma integration and earmarked $€ 200,000$ for demand-driven comprehensive community projects.

Finally, the Europeanization theorists contend that Member States are more likely to channel EU resources to the areas where the social costs of reform is high, the so-called "blame avoidance" phenomena (Weaver, 1986). However in both countries the on-the-ground situation challenges these theoretical arguments. The Roma minority in Slovakia make up almost $10 \%$ of the entire population while in Spain it represents only $1.8 \%$. Having a large Roma population should be a strong incentive for Slovakia to use available funds to alleviate exclusion, especially given that the deteriorating situation of the Roma population entails social instability and represents a predicament in economic terms. Although the Roma in Spain face similar problems as to their Eastern counterparts (see Ringold, Orenstein, \& Wilkens, 2005), the small size of their population makes it "easier" to overlook their exclusion, especially considering the frail political representation of the Roma (at all tiers of government) and their lack of lobbying leverage.

In sum, the conventional arguments largely fail to provide a valid explanation of the diverging SF outputs in the two countries. This article demonstrates empiri-

\footnotetext{
${ }^{3}$ See http://insideurope.eu/taxonomy/term/35 for absorption and allocation data.
}

cally that the variation stems from discursive representation of Roma exclusion in overarching SF strategies which legitimizes measures not always well-suited to address problems experienced on-the-ground.

\section{Methodology}

This article presents key findings from $\mathrm{PhD}$ research on SF programming (2007-2013) adopted by Spanish and Slovak governments and implemented in two convergence regions, Andalusia and Eastern Slovakia (Kostka, 2015). Both of these regions fall under the NUT 1 convergence priority stipulated by cohesion regulation, and thus are the main beneficiaries of SF. Additionally, the majority of Roma communities and settlements are concentrated in these two regions (approximately $43 \%$ of Roma in Spain live in Andalusia while almost $80 \%$ of Roma in Slovakia reside in Eastern Slovakia), regions that also exhibit the highest level of social exclusion and unemployment (EURoma, 2010). Finally both of these regions have implemented the highest number of SF projects aimed at Roma inclusion (CSES, 2011b).

Data was collected via content analysis of the main strategic policy documents (the NSRFs and OPs) in an effort to deconstruct policy text according to preestablished analytical categories and a set of standardized questions developed by the Quing research project (2012). The content analysis was triangulated with 73 semi-structured interviews conducted with senior policy-makers, project managers and Roma advocates involved in formulation and implementation of SF programming. The use of interviews as a data collection method was based on the assumption that the participants' perspectives are meaningful, knowable, and can affect the success of the project. As such they are well suited not only for gathering "descriptive" data but also for exploration of attitudes, values, beliefs and motives. Using multiple source types allows the researcher to generate more meaning and, in turn, enhances the quality of syntheses. This method is considered most suitable for extracting information about severely under-researched topics (Leech \& Onwuegbuzie, 2007).

\section{Conceptualizing Roma Exclusion}

Before proceeding to empirical investigation it is important to analyze the concept of Roma exclusion mobilised in the framework of EU cohesion policy. While the concept has acquired important strategic connotations, by stressing structural and cultural/social processes, it remains rather elusive and subject to various interpretations. As some scholars describe Roma exclusion in terms of "not belonging" (McGarry, 2011) others conceive it in terms of the denial of citizenship rights, directing attention to institutionalized discrimination and political disenfranchisement (Nordberg, 2006). Still others contend that it is dependent on "dis- 
tance" whereby people become removed from the benefits of participating in a modern society (Woodward \& Kohli, 2001). A common denominator of these discussions is the conviction that the Roma face a set of problems which differ considerably from those faced by the majority population (i.e. spatial segregation, discrimination, low educational attainments, and intergenerational poverty) (Sigona \& Vermeersch, 2012). It is this understanding that is most pronounced in policy literature, stubbornly isolating questions concerning characteristic features of contemporary European society from questions pertaining to the living conditions of Roma communities. For example the majority of Slovak policy literature examining the causes of Roma unemployment rarely includes the analysis of macro-level factors driving labour market asymmetries (Slovak Government Office, 2011). Similarly, the EC has been reluctant to address Roma exclusion within its mainstream documents. Thus, neither the Community Strategic Guidelines on Cohesion nor the Cohesion Policy Commentaries include assessment or reference to Roma exclusion. At the same time thematic papers on Roma exclusion have been multiplying. While such a dichotomy may seem legitimate given the dramatic exclusion experienced by the Roma it nevertheless obscures the common interests of Roma people and their fellow citizens and hides an increasing level of disparities across the EU.

The discursive treatment of Roma themes is further problematized by the fractious debates about the underlying causes of Roma exclusion. Conceptual divisions often stem from different normative positions scholars and practitioners hold on the ethnic dimension of exclusion (Vermeersch, 2012). Amidst the conflicting accounts it is possible to identify two prevailing frames. One views Roma exclusion as a by-product of wider socio-economic changes and the other ascribes it to behavioural and cultural conditioning. The former relates the incidence of poverty and disadvantage to wider processes of restructuring of economies and welfare states. It sheds critical light on existing patterns and privileges perpetuated by institutional arrangements, persistent socio-economic inequalities, and discrimination. As such, it problematizes the system as a whole and argues for the reconsideration of the hierarchy of goals and the set of instruments employed to guide socio-economic progress (see Kocze et al., 2014). The latter tends to discuss Roma in relatively isolated terms. It takes the moral fabric (or cultural characteristic) of groups and not the social and economic structures of society to be the root of the problem. In effect there is a tendency to "ghettoised risk category" under a new label and to publicise the more spectacular forms of cumulative disadvantage, distracting attention from the general rise in inequality, unemployment and family dissolution affecting all classes. As noted by Drál (2008) exclusion is thus presented as a product of "adaptability" whereby people's interests, skills, or motivations function outside the core of the society which consists of people who are integrated into the sets of relationships and groups that are considered "normal".

In the framework of EU cohesion policy Roma exclusion has been presented as a multidimensional process which traps Roma communities inside an intergenerational poverty cycle (EC, 2010a). Yet this comprehensive definition has focused mainly on the "lack of skills and capabilities" among Roma communities and the need to close the gap between Roma and nonRoma in access to education, employment, healthcare and housing (EC, 2014). Critics have cautioned that Roma inclusion strategies act merely as tools for inserting Roma into mainstream society and fail to unleash structural reforms and address general decline in the inclusivity of the modern welfare state (Kovats, 2012). As such the onus is being placed on the minorities to make the adjustments and accommodations deemed necessary for social cohesion (Rorke, 2014). Empirical data confirms these criticisms by showing that the majority of SF initiatives took the shape of training and consultancy measures, with very few schemes directed at institutional modifications and equality measures (Kocze et al., 2014).

The representation of Roma exclusion in the SF programming implemented in Andalusia and Eastern Slovakia mirrors the vexing dispute between those who see exclusion as a product of discriminatory practices, norms and behaviours within public institutions and those who attribute it to inadaptability of certain groups or individuals. The next section demonstrates empirically these conceptual differences and the way they influence proposed action plans.

\section{Representing Roma Exclusion}

The content analysis of the Spanish and Slovak SF programming demonstrates that the diagnosis of social exclusion in the documents differs substantially, both in terms of defining the underlying causes of exclusion and specifying the circumstances of the Roma population. In the Spanish NSRF social exclusion was defined as "a condition generated by institutional barriers, which prevent groups or individuals from fully participating in socio-economic life" (NSRF, 2007, p. 135). The preamble established that rapid social transformation of Spanish society has left the bureaucratic apparatus unprepared and not flexible enough to address instances of poverty, inequality and structural discrimination (NSRF, 2007, p. 6). Emphasis was placed on a lack of integrationist instruments, incentives and flexible procedures needed for generating equitable and accessible public services. As explained by one of the designers of NSRF:

[Spanish] institutions continue to be largely un- 
derequipped to address the new public demands and the complex realities of the Spanish society, such as an increased immigration, the disentanglement of family support system, changing gender roles, and urban poverty. Our anti-discrimination schemes continue to be quite limited and potential innovations of public interventions are constrained by the procedural complexity and inertia. (R. A. Serrano, June 14, 2011)

The majority of interviewed policy-makers, involved in the design of SF programming, admitted that SF were considered an "expedient" tool for developing a strategy of "competitiveness with a human face". The Andalusian authorities added that through the regional OP they had earmarked funds for accelerating reforms of the "sluggish" bureaucracy and developing high quality anti-discrimination framework at the regional level.

The framing of Roma exclusion in the Slovak SF programming has directed attention away from institutional and wider macro-economic factors. Although the Slovak NSRF described instances of labor demand asymmetries and uneven territorial development, it defined social exclusion in terms of "inadaptability of certain groups and individuals" and their "distance from the mainstream society" (NSRF, 2007, p. 20). The NSRF assessment explicitly stated that while some people "exclude themselves voluntarily from socioeconomic life" others are "unable, incapable or unwilling to access available rights" (NSRF, 2007, pp. 24, 56, 158). Similar assertions appeared in OPs, pointing out that the unfavorable position of marginalized citizens stemmed from a lack of "basic competences which often lead to helplessness and an inability to guide or control the decisions which have implications for day to day life" (OP E\&SI, 2007, p. 47). This framing was defended by the Slovak Ministry of Labour, Social Affairs and Family:

When talking about marginalization we need to take in consideration issues such as inadequate skills to compete in the labour market, health problems, family situation and area of residence. If we are to use SF in an effective manner these circumstantial factors need to be properly identified and assessed so the projects can be carefully tailored. We already know that a 'one size fits all' strategy does not work in practice, people are different, they deal with different problems are differently predisposed...policy action needs to take this under account. (M. Vavrinčik, May 13, 2011)

\section{Conceptualizing Strategic Targets}

The overarching strategies also developed a very different conceptualization of the main SF targets. The Spanish NSRF emphasized that SF would be directed mainly at public institutions and public agencies (not individuals or communities) in an effort to accelerate "administrative reforms and mainstream equality principle" (NSRF, 2007, p. 78). Although the NSRF and OPs internalize objectives targeted at "vulnerable groups and persons at risk of exclusion", exactly who these vulnerable citizens remained open to interpretation. The Andalusian authorities insisted that this was a conscious choice resulting from political determination to avoid institutionalizing positive discrimination, which was considered harmful to the Andalusian socialist agenda. In effect all priority axes dealing with social exclusion were not directed at specific social groups but rather at identified socio-economic problems (i.e. longterm unemployment, limited entrepreneurship, early school drop-out, informal employment).

The priority axes also remained "ethnically neutral" with no reference made to Roma minorities, their cultural distinctiveness, specific circumstances or even areas of residence. While critics argued that this omission stemmed from a limited political attention to the living conditions of Roma communities (Bereményi \& Mirga, 2012) the designers of SF programming once again insisted that introduction of ethnically specific priority axes would go against the socialist doctrine based on social solidarity and universality. They argued that a neutral approach to the Roma question was considered essential in preventing "ethnicization of poverty" whereby being Roma could be automatically equated with being excluded. A public manager from the Andalusian Ministry for Equality and Social Welfare expressed that some level of neutrality was instrumental in avoiding the promotion of "difference" over "equality". He argued that it reduced the risk of isolating the Roma question from the wider political agenda. Neutrality was also defended on the basis that transformation of public institutions would indirectly benefit all vulnerable groups including the Roma:

The main drive here is to invest in building more inclusive institutions rather than introduce independent projects targeted at excluded groups. It is not unreasonable to believe that once public institutions are prepared to support equality, those who are marginalized will benefit. Programmes directed at discriminated groups cannot be successful if governing procedures remain unchanged. (J. Navarro Zafra, June 22, 2011)

As such, the Spanish SF programming moved away from providing immediate assistance to those most affected by exclusion, opting instead for long-term systemic adjustments.

In turn, the Slovak strategic documents appeared more precise in defining excluded groups. While the diagnostic section stressed that exclusion affected various groups and individuals, it focused predominately 
on the Roma communities. The NSRF stated that "the problem of insufficient level of social inclusion is most obvious in the case of the Roma ethnic community" (NSRF, 2007, p. 21). The Roma were categorized as a group that faced greater risk of exclusion than any other faction of Slovak society (including the homeless, disabled, and immigrants). Moreover there was an explicit contention, that their situation was unique in its scope and character. The specificity of the Roma quandary was attributed to spatial factors: residence in disadvantaged and economically lagging regions and in segregated and impoverished settlements. However, the diagnosis did not explain the causes of such disadvantages, in particular common practices of spatial segregation. The interviewed NGOs attested that this omission gave rise to the false conviction that Roma intentionally choose to reside in isolation or are themselves responsible for inadequate living conditions:

Public authorities continue to focus on Roma culture and behaviour, despite a lack of data on that topic.... Instead of accounting for wider socio-economic problems, the authorities engage in rhetoric that present Roma communities as the main barriers to cohesive development. (M. Hapalová, July 23, 2011)

Indeed, the role of Roma culture in perpetuating exclusion was emphasized throughout the entire SF programming. While the NSRF stressed that "different cultural characteristics serve as barriers to meaningful integration" (NSRF, 2007, pp. 21, 23) the OPs linked cultural behaviour of the Roma to circumstances of exclusion stating that "natural socio-hierarchical rules of social life in Roma communities pose a risk for building up and maintaining communication barriers" (OP E\&SI, 2007, p. 63). In this manner SF programming mirrored widely held political perceptions that Roma need to change in order to benefit from systemic provisions.

\section{Acknowledging Structural Discrimination}

Where the two SF programming differ most substantially is in their acknowledgement of structural discrimination. The diagnostic section of the Spanish NSRF and all relevant OPs explicitly recognized that "social exclusion is generated by systemic discrimination particularly entrenched in the area of employment" (OPA, 2007, p. 26). This acknowledgment prompted creation of the thematic multiregional OP Fight against Discrimination (OP FAD) that presented "discrimination in the labor market" as the main and most immediate cause of poverty and exclusion (OP FAD, 2007, p. 13). As explained by the Intermediate Body (IB) for the OP FAD:

Negative perceptions about groups and individuals prevent them from obtaining the same employment opportunities as the mainstream society. This is the single most important barrier to meaningful participation in the economic spheres of life. It is an institutional shortcoming that needs to be prioritized in all SF and other public interventions (B. SanchezRubio, June 13, 2011).

Nevertheless, the diagnosis fell silent on the intersectionality of discrimination and inequality axes such as ethnic origin, race, or area of residence were altogether ignored. Interviewed Spanish anti-discrimination advocates maintained that such conceptualization of discrimination failed to capture critical racism and intolerance directed specifically at the Roma community. However, senior policy-makers maintained that discrimination affected all "different groups in similar manner" (i.e. preventing them from entering the labour market and/or accessing quality public services), and that was why SF were focused on discriminatory patterns rather than on group identity. The SF programing director argued that social exclusion framed in terms of institutional shortcomings rather than group dynamics is beneficial to the overall functioning of SF programming:

Taking into account the characteristics of the problems and not the types or groups of persons affected by it, forces public authorities to consider structural revisions in service delivery. The aim is making them more accessible and inclusive to all those in need, because this effectively prevents stigmatization of certain groups or treating them in separation from mainstream strategies. (B. Sanchez-Rubio, June 13, 2011).

Consequently, the SF were earmarked for "generic anti-discrimination initiatives", aimed at warding off all forms of discrimination in the labour market. Under this approach the representation of the Roma as a unique socio-cultural category was rendered counterproductive. While critics maintained that such stance ran risk of diverting funds from anti-discrimination initiatives tackling anti-Gypsism, empirical data does not support this claim. In fact, the number of awareness rising campaigns aimed at reducing anti-Roma stereotypes has increased (Evaluation of the Impact of the Multi-Regional Operational Program Fight against Discrimination, 2013).

In turn, Slovak SF programming failed to link social exclusion to discriminatory processes. In fact, the diagnosis of Roma circumstances altogether omitted any references to institutional discrimination. As confirmed by public manager from Eastern Slovakia:

We talk about multidimensionality we talk about dependencies and critical living situation, we elaborate and analyze, but if you look carefully you will not find any references to systemic discrimination, 
as if the escalation of anti-Gypsism, the deeplyrooted prejudice in the Slovak public sector, and well documented patterns of segregation do not in any way contribute to the marginalization of the Roma. (T. Železník, July 28, 2011)

A reference to discrimination appeared for the first time in the prescriptive section of the NSRF, in a statement that all social inclusion actions would "aim to combat discrimination based on sex, race, ethnical origin, religion and beliefs, disability, age or sexual orientation" (NSRF, 2007, p. 96). Elsewhere, discrimination was neither defined nor properly assessed, making it impossible to infer where it was felt most acutely and who the victims and the perpetrators were. The OPs also failed to identify institutional discrimination in their diagnosis of social exclusion. As pointed by a member of the Monitoring Committee:

It has been pointed out in numerous meetings with MAs that patterns of discrimination and unequal treatment should be elaborated on, unfortunately this has never been realized and in general there is a great reluctance on part of the authorities to account for discriminatory patterns, especially within public administration, despite strong evidence of such practices. ${ }^{4}$

Consequently, the thematic priorities and objectives inside SF programming failed to elaborate on the need to tackle any forms of discrimination and less than $2 \%$ of SF was allocated towards anti-discrimination measures.

\section{Formulating Solutions: Mainstreaming Versus Targeting}

In line with theoretical expectations, the analysis found that the solutions outlined in both SF programming had built into them a particular representation of Roma exclusion. In the case of Spanish NSRF, the acknowledgment that social exclusion is driven chiefly by systemic factors prompted political commitment to the mainstreaming approach (NSRF, 2007, p.135). In the interviews policy-makers affirmed that the social inclusion action plan was aimed at tackling discrimination in employment and consolidating the principle of equal opportunity inside public services. This aim was articulated under the priority "construction of a working environment free of discriminatory practices, committed to the principles of equal opportunity, transparency and economic as well as social innovations". The emphasis was placed on the need to adjust public services and administrative procedures in order to "strengthen attention to diversity and equal opportunities" (Evaluation of the Operation Program ESF Andalu-

${ }^{4}$ Interview \#59, 2011. sia 2007-2013, 2007, p. 138). As confirmed by the manager from General Directorate for European Funds and Planning the IB of the OP ESF Andalusia:

We expect that all potential beneficiaries demonstrate how their initiatives will cater to diversity and equal access and how they will address discrimination, without such elaboration the proposed intervention is automatically rejected. To aid the process we set up equality indicators, time-frames and public budgets, we also designated bodies responsible for monitoring and evaluation invest in equality research and information exchange. (J. Moreno, June 22, 2011)

The interviewees, including local NGOs were in agreement that mainstreaming could bring attention to the long-term impact of policies and projects and facilitate expedient systemic changes (albeit rather slowly). Although, criticisms arose regarding the "unsystematic evaluation" of mainstreaming, the OPs established equality indicators, measures supporting cognitive activities, awareness-raising campaigns, and exchange of "good practices". Practical information and concrete tools were provided to the Managing Authorities in order to ensure that mainstreaming becomes an integrated part of their everyday work. While this process was not free of delays and resistance of the cadres, all interviewees insisted that at least it was put in place. At the same time the endorsement of mainstreaming strategy has ousted approaches targeted at specific groups or communities, as only one out of fifteen thematic objectives aimed to address employability of persons at risk of exclusion through targeted measures.

In the case of Slovak NSRF, focus on individual adaptability informed the adoption of a targeted approach. The majority of interviewees asserted that SF were seen as tools for developing "insertion" projects targeted at specific and "well-defined" groups. Social inclusion objectives within the OPs called for preparing and training excluded groups, so that they could participate in all aspects of socio-economic life. The strategy relied on slogans such as "catch up", "activate" or "motivate", all of which accentuated the need for behavioural change of the target group. As commented by a public manager working for the MA for OP E\&SI:

SF can be a great tool for helping vulnerable groups develop their potential, so that they can partake in socio-economic activities on an equal footing with other citizens, SF projects can equip them with necessary skills, for example help them to complete secondary education. (R. Drienska, May 11, 2011)

The OP E\&SI also emphasized the need to invest in human resources in order to break patterns of welfare dependency and assist excluded groups in accessing public 
services and benefit from advancement mechanisms (OP $E \& S I, 2007$, p. 45). The objectives called for the "integration of excluded groups and individuals" into the institutional landscape, with references made to adaptability, adaptation, and activation (OP E\&SI, 2007, p. 142). Attention to systemic problems was kept to minimum, focusing largely on the need to modernize existing services (i.e. through IT technology and infrastructure).

The attainment of these goals was to be achieved through national and demand-driven projects, targeted at specific thematic areas and groups-the Marginalized Roma Communities (MRC).

The NSRF stated that "the circumstances of MRC are addressed separately, as projects need to be tailored to specific community needs" (NSRF, 2007, p. 95). The OP E\&SI set up national programmes targeted specifically at Roma communities (i.e. field social work, community centers) while OP Education earmarked funds to a program supporting Roma teaching assistants. The selection criteria required potential beneficiaries to demonstrate how their projects would assist or include persons of Romani origin and applications would receive higher score for accounting for Roma beneficiaries. In effect the SF earmarked for Roma inclusion almost exclusively supported measures targeted at individuals and/or MRC-training, consultancy, vocational courses, etc. According to the Social Development Fund, $90 \%$ of these did not envision measures which could change or adjust the institutional landscape (Hojsík, M. July 7 2011).

\section{Consequential SF Outputs}

Thus far the article has demonstrated that the Spanish and Slovak SF programming conceptualized social exclusion differently which in turn influenced the content of proposed solutions. What follows is an attempt to demonstrate how these differences contributed to SF outputs.

The quantitative assessments demonstrated that Spanish SF programming committed a significant proportion of SF towards social exclusion and equality measures $(55.4 \%)^{5}$. At the same time the absorption capacity for social exclusion has hovered above the EU average (Spain $46.3 \%$, EU average $41.1 \%)^{6}$. The regional SF authorities ascribed these achievements to the strong commitment to push and consolidate institutional reforms:

The prioritization of institutional reforms by the OPA allowed us to focus our efforts...instead of introducing numerous project-calls we have opted for

\footnotetext{
5 Surpassed only by Germany and Poland (see Inside Europe 2014 available at: http://insideurope.eu/taxonomy/term/204). ${ }^{6}$ Data up to the end of year 2012 at: http://www.qren.pt/ np4/np4/?newsld=3198\&fileName=novos_Gr_Site_012013.pdf
}

two major calls, one directed at public organizations and the other at private and social ones... Given that the calls were thematically focused we avoided the inflow of miscellaneous applications, this speeded up the selection process and allowed for quicker $a b$ sorption. (J. Moreno, June 22, 2011)

This commitment allowed for creation of projects larger in size and with time frames extended beyond the funding period. What needs to be pointed out is that the Managing Authorities tended to circumvent complex initiatives in favour of simple and focused projects. As explained by the manager of IB for OP FAD:

We generally feel that it is better to implement a smaller number of projects but of greater size and capacity. The small, localized projects are useful in providing immediate practical aid, but to facilitate real transformations and policy impacts we need ambitious, large-scale, and result oriented initiatives.... We also strongly believed that such projects should be relatively "easy" to manage. From our experience as IB complexity of the management and control system discourages the usage of SF altogether. (I. Rodriguez, June 6, 2011)

Looking at fiches of Spanish ESF projects it appears that they were predominately multi-million dollar initiatives, implemented by public authorities with substantial co-financing from the public budget. For example, a total budget of $€ 41,700,000$ was allocated to the labour insertion program Acceder in the 2008-2013 period; in total $€ 72,222,833$ has been invested since 2000 (EURoma, 2010). In Andalusia, the majority of projects ran by regional OP ESF, possessed budgets reaching €5 million or more (Evaluation of the Operation Program ESF Andalusia 2007-2013, 2010). By and large the winning project applications outlined in detail the strategies for tackling systemic discrimination.

The 2013 evaluation showed that these tactics not only facilitated greater and more efficient absorption but also anchored the equality principle in all individually implemented projects. The interviewees emphasized that the focus on institutional improvements has advanced quality management, control and monitoring inside the Managing Authorities. For example in the period 2007-2011 the amount of resources that were returned to the ESF by ineffective management was only $0.07 \%$ of the expenditure incurred, while the managed funds that did not exceed the control of different audits was less than $2 \%$. Finally it was attested that institutions have increased the amount and quality of professional resources which allowed them to develop more effective social inclusion projects opened to all vulnerable groups and individuals. The IB for OP FAD Foundation Once expressed that: 
Institutional quality should not be viewed as an end in itself, but a means to create accessible and cohesive public services and inclusion projects, using SF as an instrument for improving the way institutions deal with exclusion is imperative and such style of work should be prioritized in the future programming periods. (M. Tussi, June 27, 2011)

Despite these positive developments the negligent focus on the ethnic dimension of poverty was criticised by Roma inclusion advocates. The critics stressed that neutral treatment of vulnerable groups ran the risk of by-passing the most marginalized communities. For example Bereményi and Mirga (2012) argued that the use of ESF for the Roma in Spain was limited to the nationwide programme Acceder and that its existence served as a disincentive for regional authorities to programme meaningful Roma-related activities. These criticisms were refuted by the interviewed SF stakeholders who stressed that real changes take time and lack of ethnic indicators in the SF has not meant that Roma benefited less than other groups. Empirical data appears to confirm this stance. The 2011 CSES studies demonstrate an incremental rise in the number of Roma beneficiaries. A director of the Secretariat for Roma Community within the Andalusian Ministry of Equality and Social Welfare, argued that:

The international reports often put a lot of emphasis on the number of beneficiaries while neglecting to account for institutional changes that take place. Exclusive targeting of Roma is simply not feasible, not only because of the fluidity of the Roma identity but also due to legislative restrictions regarding the collection of ethnic data. That is partly why we focus on creating services and procedures that cater to all excluded and discriminated groups. Although the impacts of our initiatives are not immediately evident this does not mean that Roma do not benefit. We've seen a flourishing of Roma activism, a growing number of high school graduates, and falling number of ethnically driven hate crimes. These improvements are directly related to changes in procedures and regulations and numerous SF projects such as social enterprises. (J. Navarro Zafra, June 22, 2011)

While managers of Andalusian SF projects appeared more sceptical about the pace of institutional changes, they agreed that the streamlining of procedures and strong focus on equality and solidarity greatly improved conditions for engaging and working with vulnerable citizens.

In turn, the sub-optimal outputs of the Slovak SF programming have been well documented. The programming was criticised for acute inefficiencies, low absorption and a re-direction of SF from envisioned goals (Hurrle, Ivanov, Gill, Kling, \& Škobla, 2012). This state of affairs could be directly linked to the endorsement of targeting strategy which failed to account for institutional shortcomings. Targeting strategy has first and foremost led to the diffusion of funds among mixed and disparate objectives and measures-over $85 \%$ of competitive allocations did not exceeded a budget of $€ 500,000$ (Grambličková, 2010). The reliance on small initiatives was also tied to a lack of secured co-financing from public budgets (only the minimum $15 \%$ was provided) and meager administrative support provided for project managers. In practice entities competing in project-calls needed to amass their own funds and operational capital (even the NGOs had to contribute an expected 15\%). This impeded the participation in project-calls of small impoverished localities and privileged "small and simple" interventions. As explained by a project manager from Banská Bystrica:

All projects directed at Roma communities were implemented by municipalities or local NGOs....neither the central nor the regional authorities contributed their expertise or extra co-financing. Not surprisingly the poorest of the poor were not able to compete with the well-off localities (...) those who did manage to get funds were only able to manage simple highly localized initiatives, nobody aspired to contribute to larger changes. (I. Mako, July 26, 2011)

Thus rather than promoting complex approaches the tendency was to introduce one-dimensional, "minor" assistance services (i.e. training, social curatorship, setting up of community centers, or infrastructural repairs).

The analysis unveiled that the targeted approach so strongly supported by the designers of OPs has neither curtailed the pervasive redirection of SF away from Roma communities nor contributed to a larger number of social inclusion projects or a higher number of Roma beneficiaries. The Regional Development Agency in Prešov attributed these dynamics to the separation of targeted measures from the regional development strategy and a lack of ample assessment of Roma living conditions:

Public servants simply lack extensive knowledge about the MRC, thus the indicators are designed according to technocratic rationales rather than assessments of the situation.... What is especially frustrating is that Roma issues are constantly discussed outside the mainstream political agenda. This leads to absurd situations, where SF are earmarked for social housing which is not specified in Slovak legisIation". (N. Fuchsová, July 26, 2011)

Other stakeholders argued that the adherence to the targeted approach in fact only reinforced the stigmatization of the Roma population and legitimized isolated 
measures disconnected from wider socio-economic development agendas ${ }^{7}$.

The analysis of project fiches showed that the majority of implemented initiatives did not internalize anti-discrimination or equal treatment goals; according to the 2011 Country Report, less than $2 \%$ of implemented projects addressed (directly and indirectly) structural discrimination. According to a Roma leader, this further dwarfed the effectiveness and impact of SF projects:

For a long time we've been saying that what needs to be targeted are the structures of exclusion and not only the excluded people, this might sound insensitive but offering training to people who live in segregated communities and face daily discrimination in employment and pretty much all other areas of life, well that is just throwing money out the window. SF should be used to change policies, tackle discrimination, promote equality ...we don't have projects like that. (V. Kokeny, May 14, 2011)

\section{Concluding Remarks}

This article demonstrated empirically that a particular framing of public problems influences the process of policy implementation and its final outputs. The analysis has confirmed that Roma exclusion is largely a constructed concept, underpinned by normative contentions about the causes of poverty and marginalization. While policy-makers rely on empirical assessments to formulate the definitions of Roma exclusion, these assessments tend to be mediated by the existing cognitive and moral maps that orient their actions and routines. In turn these politically accepted definitions legitimize a specific course of action, even if it is not needed or demanded by the final beneficiaries.

In the case of Spanish SF programming the framing of social exclusion in terms of structural barriers prompted the adoption of mainstreaming approach to exclusion. The analysis confirmed that institutionalization of mainstreaming generated an array of antidiscrimination measures that directly and indirectly benefited Roma communities. The absence of targeted strategies and negligent attention to specificities of Roma exclusion generated a counterintuitive result, as the expected redirection of SF away from the Roma did not take place. In fact the ethnically neutral approach fostered stronger political attention to patterns of social exclusion and allowed for higher allocation of SF towards social exclusion themes.

In contrast, the Slovak SF programming framed social exclusion in terms of individual or group adaptability with negligent attention given to general institutional inequalities and structural discrimination. This

7 The 2012 UNDP Report has demonstrated this empirically (Hurrle et al., 2012). neglect enforced channelling of funding towards measures that aimed to change the behaviour of target groups-Roma communities. The adopted targeted approach was supposed to offset the pervasive practice of re-directing funding from the most marginalized communities, instead leading to the isolation of Roma measures from regional and local development strategies. This de facto only reinforced the re-direction of funding to other priorities. While targeting appeared sensitive to the specificity of the conditions in the Roma settlements, it in fact contributed to the ethnicization of the problem. As confirmed by SF stakeholders the opportunity for systemic transformation was effectively lost, and the Roma could benefit only from shortlived training and consulting activities, not linked to public services or poverty reduction programmes.

These findings challenge the perceived positive influence of the targeting approach, championed by the EU and numerous international Roma advocacy organizations. It appears that targeting SF at minority groups without resources provided for institutional "transformations"-in particular the enhancement of antidiscrimination principles-is counterproductive as it leads to ethnicization of the problem and its separation from mainstream policies. This often leads to disenchantment and de-legitimization of the entire SF programming. In fact if one looks more closely, an increase in the allocation of SF towards Roma integration priorities in Slovakia has actually generated greater contestation of their usefulness in facilitating inclusion ${ }^{8}$.

\section{Conflict of Interests}

The author declares no conflict of interests.

\section{References}

Bacchi, C. L. (1999). Women, policy and politics: The construction of policy problems. London: Sage Publications Incorporated.

Bailey, D., \& De Propris, L. (2002). The 1988 reform of the European Structural Funds: Entitlement or empowerment? Journal of European Public Policy, 9(3), 408-428.

Béland, D. (2005). Ideas and social policy: An institutionalist perspective. Social Policy and Administration, 39(1), 1-18.

Bereményi, B. A., \& Mirga, A. (2012). Lost in action? Evaluating the 6 years of the Comprehensive Plan for the Gitano Population in Catalonia. Barcelona: The Federation of Roma Associations in Catalonia \& EMIGRA Group.

Centre for Strategy and Evaluation Services. (2011a).

\footnotetext{
${ }^{8} \mathrm{~A}$ similar trend could be noticed in other Eastern European countries, generally endorsing targeted approaches (EURoma, 2010).
} 
Evaluation of ESF support for enhancing access to the labour market and the social inclusion of migrants and ethnic minorities (Final Report VT:2009/058). Luxembourg: Publication Office of the European Union.

Centre for Strategy and Evaluation Services. (2011b). Evaluation of ESF support for enhancing access to the labour market and the social inclusion of migrants and ethnic minorities (Roma Thematic Report). Luxembourg: The Publication Office of the European Union.

Dąbrowski, M. (2010). Institutional change, partnership and regional networks: Civic engagement and the implementation of the Structural Funds in Poland. In N. Adams, G. Cotella, \& R. Nunes (Eds.), Territorial development, cohesion and spatial planning knowledge and policy development in an enlarged EU. London: Routledge.

Decade Watch. (2009). Results of the 2009 Survey. Retrieved from http://www.romadecade.org/news/ decade-watch-results-of-the-2009-survey/9317

De Rynck, S., \& McAleavey, P. (2001). The cohesion deficit in Structural Fund policy. Journal of European Public Policy, 8(4),541-557.

Drál, P. (2008). Symbolic processes of social exclusion of Roma in Slovak public policy discourse. Ethnicity Studies, 1(2), 85-116.

European Commission. (2004). The situation of Roma in and enlarged European Union. Luxembourg: Office for Official Publications of the European Communities.

European Commission. (2010a). The European platform against poverty and social exclusion: A European framework for social and territorial cohesion, COM (2010) 758 final. Brussels: European Commission.

European Parliament. (2011). Measures to promote the situation of Roma EU citizens in the EU. Strasbourg: European Parliament. Retrieved from http://www. europarl.europa.eu/committees/en/studies.html

EURoma. (2010). Structural funds: Investing in Roma. Madrid: Fundación Secretariado Gitano.

Evaluation of the Impact of the Multi-Regional Operational Program Fight against Discrimination. (2013). Retrieved from file://C:/Users/Johanna/Down loads/publicacion_1310empleoPersVuln_Cast\%20(1 ).pdf\%20

Evaluation of the Operation Program ESF Andalusia 2007-2013. (2010). Retrieved from http://www. juntadeandalucia.es/economiainnovacionyciencia/ fondoseuropeosenandalucia/evaluacion_fse.php

Ezcurra, R., Pascual, P., \& Rapún, M. (2007). Spatial disparities in the European Union: An analysis of regional polarization. The Annuals of Regional Science, 41(2), 401-429.

Goffman, E. (1986). Frame analysis. An essay on the organization of experience. Boston: Northeastern University Press.
Grambličková, M. (2010). Efektívnost' Využívania Fondov EÚ na Podporu Rómskych Komunít. Bratislava: Priatelia Zeme-CEPA.

Guy, W. (2012). Roma inclusion at the crossroads: Can the lessons from PHARE be learned? Roma Rights Journal, Budapest: European Roma Rights Centre. Retrieved from www.errc.org/article/roma-rights2011-funding-roma-rights-challenges-andprospects/4062/1

Hurrle, J., Ivanov, A., Gill, J., Kling, J., \& Škobla, D. (2012). Uncertain impact: Have Roma in Slovakia benefited from the European Social Fund? (Roma Inclusion Working Paper). Bratislava: United Nations Development Programme.

Kocze, A., Kullmann, A., Scharle, A., Szendrey, O., Teller, N., \& Zentai, V. (2014). Toolkit on programming the Structural Funds for Roma inclusion in 2010-20. Budapest: Open Society Foundations.

Kostka, J. (2015). Going beyond political commitments: Explaining diverging outputs in the use of European Structural Funds for Roma inclusion strategies in Spain and Slovakia (Unpublished Doctoral dissertation). Central European University, Budapest, Hungary.

Kovats, M. (2012). The EU's Roma role. Open Democracy, $11^{\text {th }}$ May.

Leech, N. L., \& Onwuegbuzie, A. J. (2007). An array of qualitative data analysis tools: A call for data analysis triangulation. School Psychology Quarterly, 22(4), 557-584.

Leonardi, R., \& Nanetti, R. Y. (2011). Multi-level governance in the EU: Contrasting structures and contrasting results in cohesion policy. RSA Research Network on Effectiveness, Added Value and Future of EU Cohesion Policy, Vienna, Austria.

McGarry, A. (2011). The Roma voice in the European Union: Between national belonging and transnational identity. Journal of Social, Cultural and Political Protest, 10(3), 283-297.

National Strategic Reference Framework of Spain. (2007-2013). Retrieved from http://www.dgfc. sgpg.meh.es/sitios/DGFC/enGB/ipr/fcp0713/p/men r/Paginas/inicio.aspx

National Strategic Reference Framework of the Slovak Republic. (2007-2013). Retrieved from http://www. nsrr.sk/en/narodny-strategicky-referencny-ramec2007-2013

Nordberg, C. (2006). Claiming citizenship: Marginalised voices on identity and belonging. Citizenship Studies, 10(5), 523-539.

Operational Programme Employment and Social Inclusion, Slovakia. (2007-2013). Retrieved from http://www.nsrr.sk/en/operationalprogrammes/employment-and-social-inclusion

Operational Program Fight against Discrimination, Spain. (2007-2013). Retrieved from http://www. empleo.gob.es/uafse/es/programando/programas 
Operativos/pdf/Lucha.pdf

Quing. (2012). Quality in gender + equality policies, integrated project. Retrieved from http://www.quing. eu/component/option,com_frontpage/Itemid,1

Ringold, D., Orenstein, M. A., \& Wilkens, E. (2005). Roma in an expanding Europe: Breaking the poverty cycle. Washington, D.C.: World Bank.

Rorke, B. (2014, June 1). Roma integration and 2a normal way of living2. Open Democracy.

Sigona, N., \& Vermeersch, P. (2012). The Roma in the new EU: Policies, frames and everyday experiences. Journal of Ethic and Migration Studies, 38(8), 11891193.

\section{About the Author}

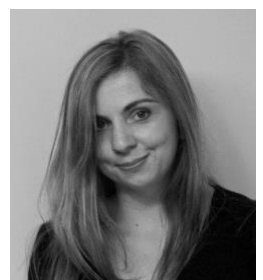

\section{Dr. Joanna Kostka}

Joanna Kostka received her Ph.D from Central European University. Her principal research interests lie in the field of policy implementation, social inclusion, and integration. She worked as a consultant and researcher for Open Society Foundation, Roma Education Fund, EU Agency for Fundamental Right and Roma Matrix project. Currently she researches integration and immigration policies implemented in Central and Eastern Europe. 